BULLETIN Bulletin hispanique

HISPANIQUE Université Michel de Montaigne Bordeaux

117-1 | 2015

Les poètes des rhéteurs

\title{
Los excesos de intertextualidad de un héroe cansado: El club Dumas de Arturo Pérez-Reverte
}

José Belmonte Serrano

\section{(2) OpenEdition}

\section{Journals}

Edición electrónica

URL: https://journals.openedition.org/bulletinhispanique/3908

DOI: 10.4000/bulletinhispanique.3908

ISSN: 1775-3821

Editor

Presses universitaires de Bordeaux

Edición impresa

Fecha de publicación: 1 junio 2015

Paginación: 345-356

ISBN: $979-10-300-0174-7$

ISSN: 0007-4640

Referencia electrónica

José Belmonte Serrano, «Los excesos de intertextualidad de un héroe cansado: El club Dumas de Arturo Pérez-Reverte», Bulletin hispanique [En línea], 117-1 | 2015, Publicado el 01 junio 2018,

consultado el 11 febrero 2022. URL: http://journals.openedition.org/bulletinhispanique/3908 ; DOI: https://doi.org/10.4000/bulletinhispanique.3908

Tous droits réservés 


\title{
Los excesos de intertextualidad de un héroe cansado: El club Dumas de Arturo Pérez-Reverte
}

\author{
José Belmonte Serrano \\ Universidad de Murcia - España
}

Émaillée d'allusions et de citations d'autres livres, une grande partie de l'œuvre narrative et des essais d'Arturo Pérez-Reverte se présente comme une immersion dans le monde de l'intertextualité. L'intertextualité littéraire affecte la conduite des personnages eux-mêmes : il en va de même pour le domaine de la peinture, du cinéma, de la critique littéraire et de la création artistique elle-même.

Mots-clés: Arturo Pérez-Reverte, intertextualité, production narrative espagnole du $\mathrm{XX}^{\mathrm{e}}$ siècle, Alexandre Dumas.

Gran parte de la obra narrativa y ensayística de Arturo Pérez-Reverte está repleta de alusiones y citas de otros libros, y se presenta como una inmersión en el mundo de la intertextualidad, intertextualidad que afecta a la conducta de los propios personajes, al igual que ocurre en el campo de la pintura, el cine, la crítica literaria y el misterio de la propia creación artística.

Palabras claves: Arturo Pérez-Reverte, intertextualidad, narrativa espańola del siglo XX, Alejandro Dumas.

Filled with allusions and quotations from other books, a great part of Arturo PérezReverte's narrative works and essays presents itself as an immersion in the world of intertextuality. Literary inter-textuality affects the behaviour of the characters themselves: and the same is true in the field of painting, movies, literary criticism as well of artistic creation itself.

Keywords: Arturo Pérez-Reverte, intertextuality, XXth Spanish narrative, Alexandre Dumas. 
«Sólo se hacen libros sobre otros libros y en torno a otros libros» Umberto Eco, Apostillas a El nombre de la rosa

$\mathrm{E}$ n uno de los apartados del libro Arturo Pérez-Reverte: los héroes cansados, en el que se recoge un buen ramillete de sentencias que el conocido escritor espańol repite en sus comparecencias ante el público o en sus artículos periodísticos, este confesaba ser, ante todo, un lector que escribe libros. $Y$ añade a continuación: «Soy un lector compulsivo que viaja con kilos de libros porque me resulta insoportable estar media hora en un aeropuerto o en cualquier sitio sin hacer nada, sin leer.» (Belmonte, 1995: 283). No nos debe resultar extraño, pues, que en todas sus obras de narrativa, así como en su producción de carácter periodístico, las alusiones a sus autores y obras predilectas sean frecuentes, hasta el punto de convertirse, acaso sin proponérselo el propio autor, en el auténtico leit motiv de buena parte de su producción. En esta última faceta, en la periodística, que ha dado lugar, hasta el momento, a la aparición de cinco extensos volúmenes donde se recogen varios centenares de sus artículos escritos entre 1993 y 2011, hay textos en los que Pérez-Reverte expresa sus gustos en materia literaria, nos desvela el título de los libros que más han influido en su formación como lector y escritor, al tiempo que nos invita, con entusiasmo y convicción, a la práctica de la lectura como fuente de información y de placer; como el venero más sólido y seguro para crecer como seres humanos. Aunque no es el principal motivo de este trabajo, podemos valernos de algún ejemplo paradigmático y muy ilustrativo. Así sucede en el artículo titulado "Asesinos de libros», perteneciente a Patente de corso, en el que Pérez-Reverte describe, con evidente tristeza y sutil lirismo, sus más profundos sentimientos al ver arder la biblioteca de Sarajevo durante la guerra de los Balcanes, en la que fue testigo de tantos desastres como reportero de Televisión Española. La parte final de este texto, rescatado ahora en un tomo de carácter ensayístico, es concluyente: "Cuando un libro arde mueren todas las vidas que lo hicieron posible, todas las vidas en él contenidas y todas las vidas a las que ese libro hubiera podido dar, en el futuro, calor y conocimientos, inteligencia, goce y esperanza. Destruir un libro es, literalmente, asesinar el alma del hombre.» (Pérez-Reverte, 1998: 46).

En la serie del capitán Alatriste, cuyas aventuras se inician en 1996 y que aún siguen su curso, con un total de siete títulos, su pasión por la literatura le ha llevado a convertir a un escritor como Francisco de Quevedo en personaje, amigo y compadre de don Diego Alatriste y Tenorio por quien está dispuesto a batirse en su defensa. Otros protagonistas, como Coy en La carta esférica, un relato sobre barcos y tesoros hundidos, es capaz de clasificar su vida utilizando como referente la propia literatura. Es decir, si nos atenemos al texto: «etapas Stevenson, y Melville, y su inevitable etapa Conrad.» (Pérez-Reverte, 2000: 221). El inicio mismo de La carta esférica no podría ser más paródico, elocuente y significativo: «Podríamos llamarlo Ismael, pero en realidad se llamaba Coy» 
(Ibid.: 13). En otros relatos en apariencia menos propicios para que nuestro autor tenga la oportunidad de desarrollar sus dotes de lector y sus vastos conocimientos de literatura, como La sombra del águila, texto aparecido, en primer lugar, por entregas, a modo de folletín, en el diario El país durante buena parte del verano de 1993, el mismísimo Napoleón, es decir el enano o le petit cabrón, como aquí se le denomina, mientras contempla el fuego de la chimenea, recuerda, a propósito de España "haber leído algo una vez, mientras esperaba que su caballería polaca despejara Somosierra" (Pérez-Reverte, 1993: 107). Ese «algo» no es otra cosa que una traducción del Poema de Mio Cid. Y por si ello fuera poco, el emperador francés también hace memoria de su experiencia al contemplar alguno de los grabados «del tal Goya», lo que le lleva a pensar en «aquellos desgraciados con sus ojos de desesperación, engañados por reyes, generales y ministros durante siglos de hambre y miseria, analfabetos e ingobernables, con su orgullo y su furia homicida como único patrimonio.» (Ibid.: 107).

Literatura y, como se puede observar, también pintura, otra de las grandes obsesiones de Arturo Pérez-Reverte, como queda reflejado con absoluta nitidez en El pintor de batallas, una de sus novelas más íntimas, más personales, más autobiográficas, en la que la acción, uno de sus recursos más utilizados y que sirve para atrapar al lector desde las primeras páginas, deja paso a la reflexión del viejo héroe cansado que busca refugio en un faro situado junto al mar, aislándose así del resto del mundo. Foulques, el protagonista de esta sólida y bien narrada historia, quiere redimir su culpa y expulsar los demonios que ha ido albergando durante su poca escrupulosa vida pintando un fresco circular en el que quiere dejar plasmados sus sueños no cumplidos y, sobre todo, esas pesadillas que le persiguen hasta el último rincón del mundo en el que trata de ocultarse. Son inevitables, pues, las alusiones a cuadros como Después de la batalla, de Giuseppe Pinacci, El triunfo de la muerte, de Brueghel el Viejo, La batalla de San Romano, de Paolo Ucello, La victoria de Fleurus, de Vicente Carducho, Escena de saqueo después de la batalla, de Aniello Falcone o El caballero, la Muerte y el Diablo, de Alberto Durero.

La insistencia del escritor cartagenero por adentrarse en los recovecos del mundo artístico a través de la creación literaria o las páginas de carácter periodístico llevó a Mendoza Fillola a realizar el trabajo «Las lanzas, pretexto para la narración». Mendoza analiza pormenorizadamente un texto de PérezReverte titulado "La fiel infantería», de 1998. Unas páginas que participan de una doble perspectiva: la histórica y la pictórica. Esta circunstancia da pie para que a lo largo de su investigación Mendoza llegue a afirmar que «la creación literaria siempre surge de la fusión de muchas referencias, de muchos contactos culturales que le imprimen fuerza creativa y que sus relaciones con otras obras no siempre podrían ser explicadas como influencia, sino como "copresencia", como coincidencia de referentes en un espacio discursivo.» (Mendoza, 2003: 264).

Partiremos, pues, de las palabras precedentes para arrojar luz sobre determinados aspectos de una de las obras literarias más representativas de toda 
la carrera literaria de Arturo Pérez-Reverte, El club Dumas, aparecida en 1993. Fue su cuarta novela publicada, tras la aparición de El húsar (1986), El maestro de esgrima (1988) y La tabla de Flandes (1990). Los lectores, y también la crítica más sagaz y exigente, saludaron con entusiasmo una obra sólida, ambiciosa y, sobre todo, bien construida, escrita con un lenguaje muy cuidado. Un libro cuya trama sedujo a Roman Polanski quien, en 1999, produjo y dirigió una versión cinematográfica titulada La novena puerta, con Johnny Deep en el papel de Lucas Corso, protagonista de esta historia.

El club Dumas es la novela de Pérez-Reverte sobre la que más se ha ocupado la crítica especializada, con extensos trabajos, a los que, en algunos casos, iremos aludiendo a lo largo de estas páginas, firmados, entre otros, por José Manuel López de Abiada, Amando López Valero, Alberto Montaner, Jean Pierre Naugrette, José Perona, Agustín Prado, Yvette Sánchez, Pia Stalder y Cécile Vilas. Esta última, precisamente, en su estudio titulado «De incunables, xilografía y encuadernaciones: la temática del libro antiguo en El club Dumas o "Nadie lee impunemente un libro en el siglo XX" ", se hace eco de unas palabras de Joëlle Gleize, quien en su libro Le double miroir : Le livre dans les livres de Stendhal à Proust, asegura que «la cita de un libro equivale a la única mímesis posible en la literatura. Si un autor emplea el libro como uno de los constituyentes básicos de su creación, siempre podemos ver en ello una reflexión sobre la naturaleza de la literatura e incluso de la lengua» (Vilas, 2000: 458). El club Dumas es, como se puede deducir, un libro sobre libros. Y es, además, como afirma la propia Cécile Vilas, un «trayecto lleno de guińos hacia el lectordescifrador.» (Ibid.: 472). La aludida autora sigue el rastro de cada una de las obras citadas, directamente o por alusiones, en El club Dumas, dando cuenta de la edición mencionada, su descripción, así como otros datos y fuentes. Este laborioso y concienzudo trabajo le conduce a situaciones un tanto curiosas y chocantes. Así sucede con el libro titulado Tratado del Arte de la Esgrima, de un tal Astarloa, que le lleva, equivocadamente, hasta Pedro Pablo de Astarloa Aguirre, autor de una obra sobre la lengua vasca, cuando en realidad Arturo Pérez-Reverte se refiere a un libro que escribe uno de sus personajes de ficción, Jaime de Astarloa, protagonista de su novela El maestro de esgrima.

Y es que a lo largo de las casi quinientas páginas de El club Dumas hay citas textuales de 126 de autores de todas las épocas. Y alusiones a obras como $E l$ conde de Montecristo, Los tres mosqueteros, La Odisea, Madame Bovary, El rojo y el negro, El Quijote, La divina comedia, Robinson Crusoe, El diablo enamorado, Memorial de Santa Helena, Guerra y paz, La colina de Watership, Un escándalo en Bohemia, etc. José Perona, en su trabajo «Historias de libros en tres novelas de Arturo Pérez-Reverte», sospecha que en El club Dumas subyace un homenaje por parte de Pérez-Reverte al escritor italiano Umberto Eco, y también a las bibliotecas míticas de Jorge Luis Borges. $\mathrm{Y}$ añade:

Arturo escribe los libros como si viviera en ellos, de ellos, con ellos y junto a ellos, como si se explicara la vida con ellos, como si, nuevo don Quijote, según Michel Foucault, "se detuviera en todas las marcas de la similitud y todo fuera lenguaje, texto, 
hojas impresas, libros ya transcritos" y, gracias a él, pareciera como si la historia de los libros, o de los cuadros, o de las variaciones de la Ofrenda de Bach, no sólo hubieran existido y explicado el mundo, sino que configuraran el presente en cuanto los personajes y nosotros sus lectores, como diría Umberto Eco, no sólo estamos leyendo, sino que "estamos tratando de comprender algo que ha sucedido entre hombres que viven entre los libros, con los libros, de los libros y, por tanto, es importante lo que dicen sobre los libros". (Perona, 2000: 375-376)

La rica, variada y compleja estructura que presenta El club Dumas lleva a Pia Stalder a definir la novela como «un entramado de elementos conceptuales $[\ldots]$, prácticos $[\ldots]$, técnicos $[\ldots]$, hipotextuales $[\ldots]$, biográficos $[\ldots]$, de crítica literaria y social, y de la transposición de todos estos elementos a un nivel intranovelesco dado por real que termina, sin embargo, por tambalearse» (Stalder, 2000: 450). Aunque no es nuestra intención abundar en lo referente al argumento de la novela, sí hay que recordar, no obstante, que estamos ante uno de los típicos héroes cansados de la narrativa revertiana, Lucas Corso, al que se le define como cazador de libros por cuenta ajena. Y mercenario de la bibliofilia. Es decir, el encargado de colmar los caprichos de ciertos ricos que no saben vivir sin una biblioteca repleta de incunables a su alrededor. $Y$ es, además, «uno de esos lectores compulsivos que devoran papel impreso desde la más tierna infancia» (Pérez-Reverte, 1993: 20). Después de ciertos avatares, llegan hasta su manos Las nueve puertas del reino de las sombras, un volumen in-folio editado en Venecia en 1666, y el manuscrito del capítulo cuarenta y dos de Los tres mosqueteros, «El vino de Anjou». Justo en ese instante comienzan las complicaciones y lo más interesante de la novela se pone en movimiento.

Un libro sobre libros llega a dar mucho de sí si su autor, en esta caso PérezReverte, posee la astucia, la habilidad y la inteligencia suficientes. En el caso que nos ocupa, la trama se ve invadida por constantes alusiones literarias, por continuos guiños al lector al que se le propone un juego adivinatorio, y hasta cierto punto divertido, en el que se ve en la obligación de participar. Véase el siguiente ejemplo, con una obra artística, en este caso, como protagonista. ¿A qué cuadro se refiere el autor cuando sólo se nos aportan los siguientes datos?: «-Hay un cuadro en el Prado, ¿̇recuerdas, Corso?... Hombres con navajas frente a jinetes que les dan sablazos. Siempre tuve una certeza: el ángel caído, al rebelarse, tenía la misma mirada, idénticos ojos extraviados que esos infelices de las navajas. El valor de la desesperación» (Ibid.: 290). Es probable que se refiera al cuadro de Francisco de Goya La carga de los mamelucos en la Puerta del Sol, pintado seis años después del levantamiento popular por el artista aragonés. $\mathrm{O}$ ¿a qué canción se refiere cuando nos habla de una música melancólica, en francés, en la que una muchacha de un bar, en un puerto, se enamora de un marinero desconocido, y cuando éste se larga para siempre la joven se queda contemplando la silla vacía y el círculo húmedo de su vaso en la mesa? Podríamos deducir que, casi con toda probabilidad, se alude a la canción de Isabelle Aubret Le gars de n'importe où, que finaliza "Et tout s'en va avec lui,/ sa chanson, sa lumière, / la fumée de sa pipel et le rond de son verre». La vida como un juego. Y los libros, las canciones o los cuadros, como un espejo de la vida. 
La devoción por el viejo Alexandre Dumas - del que, incluso, aparece en la obra la reproducción de una de las últimas fotografías, la que posa con rostro feliz junto a su amante Adah Menken- es evidente, inexcusable. Se nos ofrecen, por ejemplo, los títulos de todas sus novelas publicadas por entregas, desde sus Escenas históricas, publicada en 1831 en la Revue des Deux Mondes, hasta La hija del marqués, aparecida en 1866 en Le Siècle. En la introducción en cursiva de El club Dumas, antes del capítulo primero, «El vino de Anjou», aparece un hombre ahorcado y con las manos atadas. En el suelo hay un jarrón roto y un libro abierto por una página subrayada con lápiz rojo: «El libro era un viejo ejemplar de El vizconde de Bragelonne, una edición barata encuadernada en tela. Inclinándose sobre el hombro del agente, el juez le echó un vistazo al texto marcado: -Me han vendido -murmuró-. ¡Todo se sabe! -Todo se sabe al fin -repuso Porthos, que nada sabía.» (Ibid.: 12)

Pérez-Reverte ha manifestado en más de una ocasión que Los tres mosqueteros fue la obra que, como lector, le marcó para siempre desde su más tierna infancia. Transcurrido el tiempo, el interés no sólo se dirige a la trama, a la trepidante acción, sino, asimismo, a esos otros aspectos internos de la confección de la novela. De ahí que, descendiendo a la propia cocina del escritor, salga a relucir el curioso proceso de redacción que Dumas, previo pago, compartió con otros compañeros del oficio que, desde el silencio y casi el anonimato, también pusieron su sabiduría sobre el papel:

La técnica era complicada [...]. Dumas trazaba el plan de cada obra y lo discutía con su colaborador, que buscaba documentación y escribía un esbozo de historia, o una primera redacción: las hojas blancas. Después Dumas reescribía en las hojas azules... Trabajaba en mangas de camisa, por la mañana o por la noche; casi nunca por la tarde. No bebía café ni licores, sólo agua de Seltz. Tampoco fumaba apenas. Llenaba páginas entre apremios de los editores reclamando más y más. Maquet remitía el material en bruto por correo, y él se impacientaba con los retrasos. (Ibid.: 266)

Los libros son materia viva. El último consuelo de ciertas vidas solitarias. El clavo ardiendo al que agarrarse para evitar el precipicio que nos conduce al abismo existencial. Uno de los personajes de El club Dumas, el coleccionista portugués Víctor Fargas, confiesa a Lucas Corso que, ante la posibilidad de tener que vender su biblioteca, «me levantaba por las noches para vagar como alma en pena frente a mis libros. Les hablaba, acariciaba sus lomos entre juramentos de lealtad... Todo fue inútil. Un día tuve que tomar la decisión: sacrificar la mayor parte, conservando los ejemplares más queridos y valiosos... Ni usted ni nadie comprenderán nunca lo que fue aquello: mis libros pasto de los buitres» (Ibíd:: 191). Y ya hacia el final de la obra, de nuevo se apunta: «Nunca se está solo con un libro cerca, ¿̇no cree?... [...] Cada página nos recuerda un día pasado, revive las emociones que lo llenaron. Horas felices señalados con tiza, sombrías, sombrías con carbón...» (Ibid.: 434).

La alargada sombra de Quevedo, que tres años después de la publicación de El club Dumas habría de convertirse, como ya se apuntó, en uno de los protagonistas de El capitán Alatriste, planea sobre estas páginas. Ni qué decir 
tiene que el referente es el soneto quevedesco que arranca con este espléndido cuarteto: «Retirado en la paz de estos desiertos/ con pocos, pero doctos libros juntos,/ vivo en conversación con los difuntos/ y escucho con mis ojos a los muertos». No faltan en este entretenido viaje por el mundo de los libros las alusiones al oficio de crítico, así como a todo lo referente a la creación literaria. La mayor parte de estas nociones se hallan recogidas en el capítulo primero de El club Dumas, «El vino de Anjou». En esas páginas tiene lugar el encuentro entre Boris Balkan, traductor, habitual de las universidades de verano, experto en novela popular del siglo XIX y conocido e influyente crítico cuyas recensiones aparecen en suplementos y revistas de media Europa, y Lucas Corso, quien acude a su casa con el manuscrito del capítulo cuarenta y dos de Los tres mosqueteros bajo del brazo. Balkan, al que no le importa que le tachen de vanidoso, se considera a sí mismo «una especie de bonzo de las bellas letras» (Ibid.: 130) que cada vez que abre la boca la gente se queda en suspenso, dispuesta a oír dogmas de fe. Y subraya: «Incluso un artículo mío, en la revista literaria adecuada, puede consagrar o hundir a un escritor que empieza» (Ibid:: 130). Y lo corrobora, no sin cierto asomo de ironía, contando una anécdota personal: «Fíjense si no en el último premio Nobel, el autor de Yo, Onán, En busca de mí mismo y la archifamosa Oui, c'est moi. Fue mi firma la que lo puso en circulación hace quince años, con folio y medio en Le Monde el día de los Inocentes. No me lo perdonaré jamás, pero así funcionan estas cosas» (Ibíd.: 130).

La relación, más o menos tormentosa, de Arturo Pérez-Reverte con ciertos críticos es bien conocida. Baste recordar que a uno de ellos le reserva el papel de encargado en un burdel de Sevilla en su novela El oro del rey, de la serie del capitán Alatriste. Escuchando el nombre del personaje es fácil de adivinar a qué crítico literario español se está refiriendo:

El burdel lo regentaba un tal Garciposadas, de familia conocida en Sevilla por tener un hermano poeta en la corte -amigo de Góngora, por cierto, y quemado aquel mismo año por sodomía con un Pepillo Infante, mulato, también poeta, que había sido criado del almirante de Castilla-, y otro quemado tres años atrás en Málaga por judaizante; y como no hay dos sin tres, esos antecedentes familiares le habían granjeado el apodo de Garciposadas el Tostao. Este digno sujeto desempeñaba con soltura el grave oficio de taita o padre de la mancebía, y engrasaba voluntades para el buen discutir del negocio. (Pérez-Reverte, 2000: 79)

La respuesta de Miguel García-Posada se plasmó en las páginas de su libro El vicio crítico, donde éste no tiene otra opción que darse por aludido: «Me han contado que el narrador Pérez-Reverte me saca en una de sus narraciones como secuaz de un bujarrón llamado Góngora, lo que debo interpretar como respuesta "crítica" a mis silencios ante una obra que no me parece ni buena ni mala; sencillamente creo que no tiene nada que ver con la literatura canónica.» (García Posada, 2001: 116). Ni qué decir tiene que hubo contra réplica por parte de Pérez-Reverte, esta vez en su página de El Semanal, correspondiente al 22 de octubre de 2006, con el significativo y no menos quevedesco título 
de «El alguacil alguacilado». En muy corto espacio el novelista cartagenero hace un repaso de los "hallazgos estilísticos» de García-Posadas en la que fue por entonces su primera novela publicada, La sangre oscura. Y señala, ya en las conclusiones: «Vale la pena que se vendan cien o doscientos ejemplares de la novela, e incluso más. Es la mejor manera de que algunos lectores sepan en manos de qué individuos -los hay respetabilísimos también, pero este pobre hombre preside el gremio- se encuentra la crítica literaria en España.»

El club Dumas es, además de lo ya apuntado, un auténtico hervidero de teoría literaria. Quizá la novela de toda la producción revertiana donde más claramente se manifiesta la intención de ofrecer a sus lectores una poética personal. A lo largo de esas páginas se justifica la actitud de Dumas a la hora de crear su mundo novelesco, cuando el autor de Los tres mosqueteros repetía, una y otra vez, que el hombre no roba, conquista, saliendo así al paso de algunas acusaciones de plagio:

¿Qué otra cosa es la creación literaria? En su caso, la historia de Francia suministró el filón. El truco era extraordinario: respetar el marco y alterar el cuadro, saquear sin escrúpulos el tesoro que se le ofrecía... Dumas convierte a los personajes principales en secundarios, los que fueron humildes segundones se vuelven protagonistas, y llena páginas con incidentes que en la crónica real ocupan dos líneas... Jamás existió el pacto de amistad entre d'Artagnan y sus compañeros, entre otras cosas porque algunos ni se conocieron entre ellos... Tampoco hubo ningún conde de la Fère, o más bien hubo muchos, aunque ninguno se llamó Athos. Pero Athos existió; se llamaba Armando de Sillègue, señor de Athos, y murió de una estocada en un duelo antes de que d'Artagnan ingresara en los mosqueteros del rey. (Ibid.: 27)

Decíamos líneas más arriba que Lucas Corso es un lector, ¿pero ante qué clase de lector nos encontramos? Podríamos dar algunas pistas. Para él todo lo que le rodea tiene relación con la literatura. Es miembro de una curiosa Hermandad de Arponeros de Nantucket. Y no niega haber imaginado llevar a cabo una segunda versión, recreada, de Moby Dick:

Ismael escribe la historia, introduce el manuscrito en el ataúd calafateado y se ahoga con el resto de la dotación del Pequod. Quien sobrevive es Queequeg, el arponero salvaje y sin pretensiones intelectuales. Con el tiempo aprende a leer y un día se enfrasca en la novela de su compañero, para descubrir que la versión de éste y sus propios recuerdos de lo ocurrido no tienen nada que ver. Entonces escribe su versión de la historia. «Llamadme Queequeg», empieza, y la titula: Una ballena. (Ibid.: 366)

¿Qué clase de lector es Lucas Corso, nos preguntábamos, quien, en no pocas ocasiones, tiene la sensación de haber leído en alguna novela todo lo que le está sucediendo? El narrador de El club Dumas, un traductor y crítico literario con escasos escrúpulos, Boris Balkan, lo define como «lector cualificado y protagonista» (Ibid.: 254). Páginas más adelante el propio Balkan hace una clara distinción entre lectores elementales, como Enrique Taillefer, el personaje que aparece ahorcado en los prolegómenos de la obra, y esos otros lectores que van más allá; es decir, que no se resignan al estereotipo. Y pone un claro ejemplo, extraído, cómo no, de Los tres mosqueteros: 
D'Artagnan valiente, Athos caballeresco, Porthos bondadoso, Aramis fiel... ¡Dejen que me ría -y su risa sonó, en efecto, dramática y siniestra como la de Milady-. Nadie tiene la menor idea. ¿¿Sabe la imagen que conservo de todo ello, la que siempre admiré?... Esa dama rubia, leal a una idea de sí misma y a quien ha elegido como jefe, luchando sola, con sus propios recursos, miserablemente asesinada por cuatro héroes de cartón piedra... ¡Y ese hijo oculto, huérfano, que aparece veinte años después! [...]. Recuerdo el grabado como si lo estuviera viendo en ese instante: un río, la noche, los cuatro canallas, arrodillados pero sin piedad. Y al otro lado, el verdugo que levanta la espada sobre el cuello desnudo de la mujer. (Ibid.: 411)

El contrapunto más genuino y mejor logrado de Lucas Corso lo encontramos en su novela La piel del tambor. Es el caso opuesto a Corso. De manera paródica, casi esperpéntica, como si Reverte se hubiera dejado influir por la más fina técnica del cómic, pone en pie a un personaje llamado don Ibrahim - «grande, muy gordo, de aspecto bonachón y apacible apenas desmentido por el fiero bigote» (Pérez-Reverte, 1995: 57)- que se pasea por las calles de Sevilla ejerciendo la profesión de abogado, aunque sin poseer ningún título universitario que le avale. Un estafador y un sinvergüenza, como se le define en estas páginas, aunque, eso sí, un perfecto caballero. También don Ibrahim, al igual que Corso, es un lector. Pero un lector, al contrario que éste, sólo por encima que, además, atesoraba citas como oro en paño: «En lo tocante a sueños, la mejor procedía de Thomas D. H. Lawrence, aquel fulano de Arabia que había escrito Lady Butterfly: los hombres que sueñan con los ojos abiertos se llevan el gato al agua, o algo así.» (Ibid.: 83). Se jacta, asimismo, de poseer un abollado mechero de plata, recuerdo, esta vez, «de Gabriel García Márquez, a quien conoció, decía, cuando el autor de El coronel Páramo no tiene quien le visite era humilde reportero de sucesos en Cartagena de Indias.» (Ibid.: 347).

Este discurso sirve para introducirnos en otro de los asuntos más apasionantes anexos a la propia literatura y que podemos contemplar con absoluta nitidez en El club Dumas: la reinterpretación de una obra literaria, superados los prejuicios de su tiempo y las consiguientes lecturas canónicas. Descifrar un libro resulta apasionante. Pero lo es mucho más cuando se le aplica una mirada nueva e insólita: «¿Por qué han de ser más virtuosos unos matasietes que usan a las mujeres, que aceptan de ellas dinero, que sólo piensan en medrar y hacer fortuna, y no una Milady que es inteligente y valerosa, que elige un jefe, Richelieu, y le sirve con lealtad, jugándose por él la vida?» (Ibid:: 415). En los últimos compases del relato, cuando Corso se reúne con Balkan, éste no duda en acusarle de exceso de intertextualidad; es decir, de poner en conexión demasiadas referencias literarias, por lo que su vida profesional, y también personal, está abocada al fracaso. Un lector que rellena por su propia cuenta los espacios en blanco; un lector que tiene la manía de anticiparse a los acontecimientos, de pasarse de listo:

Escuche, Corso: ya no hay lectores inocentes. Ante un texto, cada uno aplica su propia perversidad. Un lector es lo que antes ha leído, más el cine y la televisión que ha visto. A la información que le proporcione el autor, siempre añadirá la suya propia. Y ahí está el peligro: el exceso de referencias puede haberle fabricado a usted un adversario 
equivocado, o irreal [...] La información que proporciona un libro suele ser objetiva. Quizá pueda estar planificada por un autor malvado para inducirle a errar, mas nunca es falsa. Es usted quien hace una lectura falsa. (p. 457)

El exceso de intertextualidad puede llegar a provocar, incluso, situaciones cómicas, como sucede cuando alguien le plantea a Corso la posibilidad de ir a la policía para acabar con toda esta serie de intrigas y sucesos que lo han convertido en una víctima: «¿Y qué les digo?... ¿Qué Milady y Rochefort, agentes del cardenal Richelieu, nos han robado un capítulo de Los tres mosqueteros y un libro para convocar a Lucifer? ¿Que el diablo se ha enamorado de mí, encarnándose en una veinteańera para convertirse en mi guardaespaldas?... Dime qué harías tú si fueses el comisario Maigret y yo viniera con ese argumento?.» (Ibid.: 381).

Las teorías del semiólogo y novelista Umberto Eco pueden ayudarnos a comprender la actitud de Lucas Corso. Eco, en su libro Interpretación y sobreinterpretación, distingue los términos «interpretación sana» e «interpretación paranoica»: «El paranoico no es la persona que observa que "mientras" y "cocodrilo" aparecen curiosamente en el mismo contexto, el paranoico es la persona que empieza a preguntarse por los misteriosos motivos que me han inducido a juntar precisamente esas dos palabras» (Eco, 1995: 51). Esa sobreestimación de la importancia de los indicios, error con el que con tanta frecuencia tropieza el protagonista de El club Dumas, nace, según Eco, «de una propensión a considerar como significativos los elementos más inmediatamente aparentes» (Ibid.: 52). Y nos ofrece, a continuación, un ejemplo muy gráfico:

Un médico se equivoca si, al darse cuenta de que todos sus pacientes que padecen cirrosis hepática beben regularmente whisky con soda, coñac con soda o ginebra con soda, concluye que la soda provoca cirrosis hepática. Se equivoca porque no se da cuenta de que hay otro elemento común en los tres casos, es decir, el alcohol, y se equivoca porque hace caso omiso de todos los casos de pacientes abstemios que sólo beben soda y no tienen cirrosis hepática. (Ibid.: 53).

Algunos de los estudiosos de El club Dumas han tratado de desvelar todo el rico y lúdico entramado intertextual de la novela. Así, Yvette Sánchez llega a la conclusión de que «el lector o la lectora dispondrán de códigos más o menos amplios para descifrar intertextualidades pero nunca parten de cero, ex nihilo, sin antecedentes "penales" de lecturas anteriores. Está fuera de uso el topos del lector inocente. Por ende, sólo los muy ingenuos seguirán culpando a los literatos de supuestos robos. La transtextualidad está absolutamente admitida en la sociedad creyente en una estética postmoderna» (Sánchez, 2000: 435). Por su parte, José Perona va más allá e interpreta el exceso de intertextualidad de que sufre Lucas Corso como «un argumento para abrumar al lector, porque éste debe abstraerse de la verdad aterradora que postula que en el fin de siglo las cosas y el lenguaje se han separado, que la realidad ya no es como los libros ni está en ellos, y recuperar aquella nostalgia de la infancia, del humanismo o del romanticismo, donde sí era verdad que la clave eran los libros. Que, para decirlo con la exactitud de los clásicos, historia est magistra vitae» (Ibid.: 376). 
Finalmente, para López de Abiada Corso es, por su deformación profesional y, sobre todo, a causa de su portentosa memoria literaria, «la víctima ideal de los juegos de la intertextualidad.» (López de Abiada, 2003: 227). Y añade más adelante: "Corso acaba enredado en la telarańa de la trama y en los mismos sucesos de un folletín, víctima de su exceso de intertextualidad.» (Ibid.: 29).

Cabría preguntarnos, ya para concluir estas páginas, qué es lo que aporta este juego intertextual en obras como la de Arturo Pérez-Reverte que hemos intentado analizar. Y para responder con mayor exactitud a esta cuestión nos permitimos regresar al trabajo citado con anterioridad de Mendoza Fillola sobre un texto del propio Pérez-Reverte, con el cuadro de Las lanzas como telón de fondo. Mendoza asegura que

cuando se afirma que la literatura es interactiva, precisamente se subraya que en su discurso siempre hay elementos, componentes o referentes que apelan a que el lector busque, entresaque y active sus conocimientos y los ofrezca como aportaciones a ese proceso de interacción, que no es más que la más personal recepción de una obra de creación. La presencia intertextual refuerza el efecto interactivo porque hace que el receptor reconozca y valore las referencias que aporta el texto. (Ibid.: 263)

\section{Obras citadas}

Belmonte Serrano José, Arturo Pérez-Reverte: los héroes cansados, Madrid, Espasa Calpe, $1995,301 \mathrm{p}$.

Eco Umberto, Interpretación y sobreinterpretación, Nueva York, Cambridge University Press, 1995, $164 \mathrm{p}$.

García Posada Miguel, El vicio crítico, Madrid, Espasa, 2001. 200 p.

Gleize Joëlle, Le double miroir : Le livre dans les livres de Stendhal à Proust, Paris, Hachette, 1992, 285 p.

Lopez de Abiada José Manuel, «Para una gramática del best-séller desde el canon literario: El club Dumas como paradigma», en Belmonte Serrano José, Sobre héroes y libros. La obra narrativa y periodística de Arturo Pérez-Reverte, Murcia, Nausícaä, 2003, p. 185-237.

Mendoza Fillola, Antonio, "Las lanzas, pretexto para la narración», en Belmonte Serrano José, Sobre héroes y libros, p. 263-286.

Pérez-Reverte Arturo, El club Dumas, Madrid, Alfaguara, 1993, 493 p.

- La sombra del águila, Madrid, Alfaguara, 1993, 151 p.

- La piel del tambor, Madrid, Alfaguara, 1995, $589 \mathrm{p}$.

- Patente de corso, Madrid, Alfaguara, 1998, 527 p.

- La carta esférica, Madrid, Alfaguara, 2000, 590 p.

- El oro del rey, Madrid, Alfaguara, 2000, 267 p.

- El pintor de batallas, Madrid, Alfaguara, 2006, $301 \mathrm{p}$.

Perona, José, «Historias de libros en tres novelas de Arturo Pérez-Reverte», en López de Abiada José Manuel, Territorio Reverte. Ensayos sobre la obra de Arturo Pérez-Reverte, Madrid, Verbum, 2000, p. 368-388. 
Sánchez Yvette, «De bibliófilos culpables y lectores inocentes en El club Dumas», en López de Abiada José Manuel, Territorio Reverte, p. 423-435.

Stalder Pia, "Aproximación a tres personajes principales de El club Dumas», en López de Abiada José Manuel, Territorio Reverte, p. 447-457.

Vilas Cécile, "De incunables, xilografía y encuadernaciones: la temática del libro antiguo en El club Dumas o 'Nadie lee impunemente un libro en el siglo XX'», en López de Abiada José Manuel, Territorio Reverte, p. 458-480. 